\title{
Urban regeneration of GCC cities: preserving the urban fabric's cultural heritage and social complexity
}

\begin{abstract}
Urban Planning is the activity aiming at organizing the urban space, ordering the land use and the built environment where human activities take place. In the past decades cities located in the GCC have experienced a concurrent rapid urban development and regeneration. Scholars stress that ${ }^{1}$ in the past two decades the urban planning process, which has led the urban growth of GCC cities, has been mainly based on western patterns with no much consideration of the unplanned urban evolution and social complexity of the city, and that ${ }^{2}$ land speculation has succeeded in distorting the intended orderliness of urban space. This approach to urban planning has resulted in the urban regeneration and modernization of the built environment with a philosophy based on land speculation and urban sprawling causing negative effects on the live ability of cities. The effects of land speculation and sprawling consist of poor land subdivision and dominance of private residential land use over recreational and public land use which represented the vibrant unplanned and social nodes enhancing the live ability of the urban space.
\end{abstract}

This paper argues that in order to plan the urban growth of GCC cities and to pursue modernity, a comprehensive urban planning strategy should be aiming at preserving and regenerating the city's $\mathrm{s}^{1}$ cultural heritage (or historical urban evolution) $a^{2} \mathrm{~d}^{2}$ social complexity, which are source of generative ideas and principles for the design of liveable communities.

Keywords: urban planning, urban sociology, cultural heritage, public realm, urban sprawling
Volume I Issue I - 2017

\author{
Raffaello Furlan, Laura Faggion \\ Department of Architecture and Urban Planning (DAUP), \\ College of Engineering, Qatar University, Qatar
}

Correspondence: Raffaello Furlan, department of Architecture and Urban Planning (DAUP), College of Engineering, Qatar University, Qatar, Email raffur@gmail.com

Received: November 4, 2016 | Published: March 07, 2017

\section{Literature review}

The process of globalization or of global transformation is commonly operated at the level of economics and built environment. Globalization contains multi-faceted dimensions such as trade and finance which commonly impact on the urbanization and/or global restructuring of cities. ${ }^{1,2}$ Through the past few decades, as a result of globalization and also favored by the discovery and trade of oil, which transformed the economy of Gulf Cooperation Council (GCC)Arab countries (Bahrain, Kuwait, Oman, Qatar, Kingdom of Saudi Arabia, United Arab Emirates), several GCC cities experienced a rapid urban growth. ${ }^{3-7}$ Cities in the region have been transformed from villages to metropolis: wide road networks and public transit systems have been developed old courtyard houses districts have been replaced with modern high rise business neighbor hoods, large scale shopping malls have been planned in the periphery of cities, replacing old traditional downtown Souks. ${ }^{8}$ In turn this urban planning strategy has contributed to change the typical single-core to multiple-core city, structured on new urban villages built around train stations planned along new public transportation systems, such as the Metro and Light Rail Train (LRT). ${ }^{9-19}$

Critically, scholars stress that the urban growth conceived by contemporary urban planners in the GCC is based on western urban planning approaches, which lead to common modes in managing urbanization: real estate finance plays a crucial role for the urban development of cities. Funds are invested from the moment the developer wants to "tie up" land, through pre-development approvals, construction, lease-up, or sell out investors and providers of funds expect a fast financial return. With the booming of the real estate market, the prices for building areas increased and consequently land speculation has become the attractive trend. Therefore, globalization has a severe impact on land speculation and consequent urban sprawl of large developing GCC cities. ${ }^{20-25}$

Furthermore, the literature reveals that globalization leads to the disappearing of cultural features, which are embedded into the built environment. Several macro-scale projects are funded by international companies, who invest large funds, expect large profit and neglect those traditional or socio-cultural aspects, which have contributed to formation of the built environment of cities for centuries. ${ }^{26}$ In turn, this lack of consideration leads to create precincts where live ability are diminished, due to lack of accessible open spaces commonly used for social activities. Scholars urge the need to embrace a comprehensive urban design vision for the development of GCC cities: the rapid evolution of the city should lead to new spatial transformations which, consequently, shape the built environment that accordingly reflects its inhabitants' cultural and social needs rather than neglecting their consideration. The enhancement of smart urban growth should be based on pillars such as economic development, social cohesion and sustainability, environmental and heritage conservation: this strategy would lead to the conception of sustainable communities. ${ }^{9-11,16,19,27}$

\section{Smart urban growth}

In the past decades local government and/or municipalities ${ }^{1}$ started to embrace and encourage 'smart growth' by launching appropriate urban planning strategies and ${ }^{2}$ introduced strict requirements through urban zoning guidelines, in order to stop and/or limit urban sprawl. This approach contributes in reducing private land speculation, increasing urban density and battling urban sprawl. In addition, scholars argue that the absence of public open spaces such as plazas, squares at the end or intersection of streets is evident along new residential development. The lack of nodes acting as connecting points and/or public spaces utilized for pedestrian gathering areas and/or for 
a variety of commercial, recreational and social activities contributes to enhance the live ability of the urban fabric of the city. Commonly, these public open spaces-nodes or plazas, constituting an integral part of the community's social life, are replaced by roundabout, which serve vehicular movement only.

Also, it is common to witness that traditional common nodes have been replaced by isolated shopping malls located within the outskirt of the city and therefore accessible only by vehicular system. Air-conditioned shopping malls, perceived as a destination, provide shopping opportunities and offer indoor facilities for users' recreational activities. Namely in GCC countries, the emphasis on air-conditioning buildings has directed the city design to focus on indoor spaces. Though, the feeling of the fresh air as well as of space supporting outdoor activities is missed. ${ }^{28-31}$

Streets are designed for vehicle accessibility and comfortable side-walk is often not existing or neglected: street furniture, shading devices, colonnades or green elements, providing a sense of activities and a perception of safety and comfort, are commonly missed. Due to increased urbanization and vehicular traffic, as well as a lack of adequate design and planning, old streets are not integrated with the urban fabric of cities and simply designed as traffic-oriented space. These old vibrant streets are usually disconnected from the city's main body, resulting in a decrease of live ability of public and commercial spaces. In turn this disconnection contributes to a socio-physical decline of the built environment. ${ }^{32}$

Therefore, urban designers and planners are envisioning the development of public realms and arrangement of streets and landscape areas, in order to contribute to create vital urban spaces. Plans by local authorities are advised to be in place to focus on the smart growth of open spaces, neighborhood revitalization in order to create attractive, vibrant and liveable communities. This approach provides new hypotheses for interdisciplinary research, encouraging an integral link among multifaceted disciplines such as urban design, architecture, social sciences and/or urban sociology. This transdisciplinary collaboration has the potential to build robust knowledge towards the construction and/or implementation of more cohesive urban fabric, where streets and nodes shift from being the residual areas of private developments to becoming the dominant landmarks of the urban fabric, contributing to enhance live ability of the city. ${ }^{12,33-36}$

Finally, scholars and practitioners urge the necessity to develop a new conceptual framework for exploring the formulation of priorities regarding strategic urban planning. The framework needs to encompass global/local interaction: open spaces should be threatened by urban expansion, more dense/compact urban villages developed around public transit are required in order to reduce automobile use and traffic congestion and contribute to the preservation of the natural environment day 2003. Namely, the restructuring of nodalspaces involves the consideration of social and physical structures. City planners seem to face a number of challenges from economic restructuring. However, the global city model is seen as too reductionist and neglecting socio-cultural factors, which have played a determinant role in the formation of cities since the early days of civilization and nowadays should not be erased due to speculative interests.

\section{Urban sociology: built form and human activities}

Due to the need to humanize the built environment and to create spatial environments responding to users cultural needs, social researchers pointed out the necessity of re-evaluating a theoretical cultural framework for planning the city and its built forms. ${ }^{37-39}$ This approach aiming to humanize spatial environments is defined as humanistic in opposition to a 'formalistic approach', which focuses mostly on the appearance of buildings. ${ }^{40}$ In response to the recognition that much contemporary urban design, in its pursuit of economic efficiency, has paid little attention to its human context, the last two decades of urban studies have been marked by a renewed interest in the way designed built environments are related to users socio-cultural needs as expressions of culture as way of life. ${ }^{41}$

It was in the 1980s that researchers with various social sciences background explored the relationship between human context and designed physical environments. Urban sociology, a specialized field defined as the study of how human behavior and/or activities are projected onto the spatial form of the built environment, emerged during this time $e^{42,43}$ argue that the built environment and occupants human behavior and/or activities interact continually. Additionally they stress that human behavior is influenced by culture as a way of life because behavior and culture interrelate repetitively throughout development. This means that the role of culture must also be explored because it plays a crucial role into the relationship between spatial environment and human behavior. ${ }^{44-46}$ Namely sociologists argue that the extent to which the users shape the form of their settings in response to human needs which are expression of culture as a way of life can be revealed through the analysis of human behavior and/ or activities. Therefore, sociologists stress the need of applying their theories and research methods to the urban and architectural design process in order to create designed physical environments responding to user's specific needs. ${ }^{47}$

\section{Sustainable urbanism}

Sustainable urbanism is the application of both sustainability and resilient principles to the design, planning and development of cities. The emerging movement of sustainable urbanism is primarily focused on designing smart and compact communities that enhance walk ability. Compactness and density are essential roles in sustainable urban developments as contributing to reduce per-capita resource use. Low-density developments on the other hand encourage urban sprawl where transport relies on high dependence of private automobiles. ${ }^{33}$ The movement of sustainable urbanism aims at enhancing live ability by ${ }^{1}$ offering individuals a wider range of healthier living choices $^{2}$ creating a greater sense of community in order to promote participation, integration and engagement ${ }^{20}$ expanding opportunities ${ }^{3}$ promoting greater equality in order to create an economically city for a walk able environment ${ }^{20}$ fostering sustainability to create a more environmentally friendly society for the people..$^{35}$

Since the discovery of oil, Urbanism in GCC countries entered a new development phase due to globalization and/or westernization, which casted the foundation of urban life changes. The built environment of Islamic cities experienced major developments, namely in social, cultural, economic and sustainability dimensions. The desire for rapid growth of cities and the concurrently creation of new cities with transformed modern forms has partially contributed to forget or neglect to apply those secular vernacular/traditional principles, which formed the foundation of sustainable urbanism, communities or neighborhoods based on culture as a way of life. Nowadays the international tendency is to only pursue specific environmental rating systems (i.e. Green Star in Australia, LEED in USA and BREEAM in UK) to certify the level of sustainability 
achieved with new constructions and/or with a neighborhood design, based on their latest criteria adapted for community design. ${ }^{48}$ This certification program is an accepted benchmark for the design and construction high performance green buildings, providing clients the tools to measure the impact on their buildings performance. Theoretically this laid the foundation for the design of the sustainable city where the relationship between human sustainable environment and development is addressed in both urbanism and architecture with the aim of creating balance between biological needs and preservation of the natural environment however without addressing culture as a determinant factor.

\section{The Islamic city: cultural heritage and social complexity embedded into the urban fabric}

In his milestone treatise called 'De Architectura' translated as 'The Ten Books on Architecture', Marcus Vitruvius Polio declared 'Firmitas' (stability), 'Utilitas' (utility) and 'Venustas' (beauty) to be the three fundamental characteristics of the discipline of architecture. ${ }^{49}$ Also, contemporary architectural theorists argue that architecture is always concerned fundamentally with three interrelated factors. Additionally, Vitruvius stressed that, aside from the structural, the functional and the aesthetic ${ }^{50}$ culture is an essential factor to the field of architecture. In his words 'Architecture is the art and science of designing buildings and structures, addressing aesthetics, function and cultural purposes. ${ }^{49}$ The classical view of the discipline by Vitruvius is shared by contemporary scholars and researchers. Schopenhauer stresses how the built form is influenced by cultural differences in user's way of life. In his words 'Even at the primitive stage of human dwellings, the slight differences in cultural inheritance and way of life can bring about considerable changes in built form and the use of space, ${ }^{51}$

Space created either at the micro scale of built forms or the macroscale of human settlements, is shaped with history or culture which define the spatial urban identity. ${ }^{52}$ The built environment must be considered as a palimpsest of historical and cultural layers, able to communicate the values of the society and their mode of settlement. ${ }^{53}$ The role of cultural heritage in the city transformation processes is based on the local identity. In Kaspirin's words 'There are three significant dimensions that interactively craft human settlements, culture, space and time (history). These interactions produce 'urban meaning' and 'urban functionality' the containers for the complex stories, metaphors, traditions, emergent patterns, and needs in human settlements.'.54

Contemporary urban designers, planners and architects are acknowledged with the 'culture, space and time urban meaning and urban functionality' of Islamic-Arab cities. Less well known however is how this knowledge has contributed to post modernity and/or to the formation and implementation of physical settlements or neighborhood of Islamic-Arab cities.

In her book Re-imaging the City-A New Conceptualization of the Urban Logic of the 'Islamic city', Falahat stresses that the study of the morphology of the city can provide an understanding of the city as a direct reflection of people way of life..$^{55}$ Therefore, she stresses the need to study the city within 'its own individual context' which has not been occurring in the past decades. In the past the morphology of Islamic cities has been identified though the geometry of the form of the street network, characterized by 'non-rectilinear paths, large number of seeming culs-de-sac, and the feeling of getting lost within the city'. These features, which contributed to create the image of the modern 'Islamic city' (early $20^{\text {th }}$ century) make the Islamic city shaped by complicated labyrinths and lacking 'order' or inorganically assembled, namely when compared with medieval western cities' urban order.

Critically, Falahat investigates the relationship between the morphology of Islamic cities and social structure and religious affairs. This approach provides acknowledgment of the distinctive structure and of a new perspective to studying the urban fabric of the Islamic cities. In Falahat's words the Islamic city is characterized by attributions such as "tortuous, crooked, curved, winding, indirect, twisting, weaving, zigzag, irregular, non-geometric, unplanned, formless, haphazard, loose structure, chaotic, no pattern, plan/os, spontaneous, ad hoc, organic, treelike, maze, labyrinth, labyrinthine, and labyrinth-like". She argues that based on regularity and order, the 'Islamic city' was depicted as 'irregular, chaotic, and ruleless phenomenon'. Therefore, she stresses the need to adopt a new approach in order to understand "what it is about the city that causes the city' in opposition to past conceptual interpretations investigating what the Islamic is not in comparison to Western cities. ${ }^{55}$

Falahat concludes that the key-factors of the structure of the 'Islamic City' are attributed to social and religious features "Islam is an urban religion and that the mosque underlies the creation of the Islamic city". In her view, this is visible though three specific physical features "the differentiation between commercial and residential quarters, the segregation of residential quarters according to ethnicity or specialization and a hierarchical order of trades in the market situating the cleaner trades closer to the mosque showing that they were ordered according to a particular hierarchy and their position was not completely accidental."As a result, buildings are not integrated into a planned pattern but they individually define the shape taken by the roads. Several blind alleys and road ways which are rarely rectilinear are then shaped. In addition to the mosque and the street networks the souk (the bazaar) and the square which disintegrated into a network of alleyways serving a variety of commercial and residential functions are the other identified elements of the 'Islamic city'. $7,55,56$

Therefore, the physical form of Islamic cities is the resultant of the relationship between spatial patterns and social organization. The Islamic city urban growth is explained mostly by concepts such as 'spontaneous, organic, natural, and like an organism' which expanded incrementally. The irregular, non-geometric and organic with incidence of crooked and curved streets is the result of an historical, spontaneous and unplanned spatial-social evolution.

\section{Implications for practice and advancement of research: the philosophy for continuity and modernization of GCC cities}

Along the history of human settlement and/or civilization, economic inputs in the form of public or private investment have always been cardinal to urban development's and/or the formation of the city. Nevertheless history teaches that built environments were not built in the past for a simplistic speculative purpose, with no consideration of users' sociological customs and/or culture as way of life. The urban fabric was conceived and built to facilitate and enhance livability as expression of culture as a way of life. Nowadays the globalizationtrend is the opposite inhabitants way of life has to drastically change to fit into globalized urban spaces designed for speculative strategies where buildings are purchased and re-sold several times before the users settle in and use them. ${ }^{57-58}$ 
Critically, users socio-cultural needs are not efficiently considered along the development of contemporary cities the literature reveals that too often the built environment is marked with building typologies such as residential compounds, apartment blocks and skyscrapers where people/users have no access to open spaces because such open spaces have been replaced by car-parks. ${ }^{13,16}$ Decentralized shopping centers accessible by cars have become the contemporary, globalized (or westernized) public real, arena for an indoor imposed sociological habit and/or way of life.

Therefore, it is argued that ${ }^{1}$ the urban planning of GCC cities cannot be based on economic, financial or speculative purposes only commonly dictated by globalization and/or westernization and ${ }^{2}$ history, identity and cultural heritage must be addressed and preserved in the drafting of urban planning policies guiding the development of the physical settlement.

\section{Acknowledgements}

Raffaello Furlan has nearly 20 years professional experience as architect and 15 years teaching experience in Italy, Australia, and in Middle East. Laura Faggion has nearly 10 years professional experience as architect and 12 years teaching experience in Italy and in Australia. The authors would like to acknowledge the support of Qatar University for creating an environment that encourages scientific research. This study was developed as part of the research project scheme UREP 19-181-5-041 "New Built Forms Integrated into the Urban Fabric of Doha" funded from Qatar National Research Fund (QNRF) University. Also, the authors would like to express their gratitude to the Government of Qatar, especially to the Ministry of Municipality and Urban Planning (MMUP) and the Qatar National Council for Culture, Arts and Heritage, for their kind assistance and attentive collaboration - for handling relevant visual data and cardinal documents supporting the purpose of this research study. Finally, the authors thank the anonymous reviewers for their comments, which contributed to an improvement of this paper.

\section{Conflict of interest}

Authors declare there is no conflict of interest in publishing the article.

\section{References}

1. Adham K. Rediscovering the Island: Doha's urbanity from pearls to spectacle. In Y. Elsheshtawy, editors. The evolving Arab City: tradition, modernity and urban development, Routledge, UK; 2008.

2. Al Asad M. Contemporary Architecture and Urbanism in the Middle East. University Press of Florida, USA; 2012.

3. Benninson AK, Gascoigne AL. Cities in the Pre-Modent Islamic WorldThe Urban Impact of Religion State and Society. Routledge, USA; 2007.

4. Hakim BS. Arabic Islamic Cities: Building and Planning Principles Routledg, UK; 2013.

5. Kazimee BA, Rahmani AB. Place, Meaning and Form in the Architecture and Urban Structure of Eastern Islamic Cities. Edwin Mellen Press. USA; 2003. p. 280.

6. Khan HU. Architectural Conservations as a Tool for Cultural Continuity: A Focus on the Built Environment of Islam. Archnet-IJAR. 2015;9(1):1-17.

7. Petruccioli A. After Amnesia-Learning from the Islamic Mediterranean Urban Fabric. IRJAH. 2007;37:1-2.
8. Wiedmann F, Salama AM, Thierstein A. Urban Evolution Of The City Of Doha: an Investigation Into The Impact Of Economic. METU. 2012;29(2):35-61.

9. Furlan R. Modern and Vernacular Settlements in Doha: An Urban Planning Strategy to Pursue Modernity and Consolidate Cultural identity. Arts and Social Sciences Journal. 2016;7(2):171.

10. Furlan R. Urban Design and Livability: The Regeneration of the Corniche in Doha. American Journal of Environmental Engineering. 2016;6(3):73-87.

11. Furlan R, Almohannadi M. Light Rail Transit and Land Use: An Integrated Planning Strategy for Al-Qassar's TOD. International Journal of Architectural Research 2016;10(3):170-192.

12. Furlan R, Almohannadi M, Zaina S, et al. Integrated Approach for the Improvement of Human Comfort in the Public Realm: The Case of the Corniche, the Linear Urban Link of Doha. American Journal of Sociological Research. 2015;5(3):89-100.

13. Furlan R, Eissa B, Awwad R, et al. Neighborhoods and Social Interactions: The Case of Al-Najada Area in Doha. American Journal of Sociological Research. 2015;5(4):119-133.

14. Furlan R, Faggion L. The Development of Vital Precincts in Doha: Urban Regeneration and Socio-Cultural Factors. American Journal of Environmental Engineering. 2015;5(4):120-129.

15. Furlan R, Faggion L. The Souq Waqif Heritage Site in Doha: Spatial Form and Livability. American Journal of Environmental Engineering. 2015;5(5):146-160.

16. Furlan R, Muneerudeen A, Khani FA. Urban Revitalization of Public Spaces in the Pearl in Qatar. American Journal of Sociological Research. 2016;6(1):1-9.

17. Furlan R, Eiraibe N, Malki AA. Exploration of Sustainable Urban Qualities of Al Saad Area in Doha. American Journal of Sociological Research. 2015;5(4):101-118.

18. Furlan R, Nafi S, Alattar D. Urban Built Form of the Souq Waqif in Doha and User's Social Engagement. American Journal of Sociological Research. 2015;5(3):73-88.

19. Furlan R, Petruccioli A. Affordable Housing for Middle Income Expats in Qatar: Strategies for Implementing Livability and Urban Form. ArchNet IJAR. 2016;10(3):138-151.

20. Maimani AA, Salama AM, Fadli F. Exploring socio-spatial Apsects of Traditional Souqs: The Case of Souq Mutrah, Oman. Archnet-IJAR. 2014;8(1):50-65.

21. Remali AM, Salama AM, Wiedmann F, et al. A chronological exploration of the evolution of housing typologies in Gulf cities. City Territory and Architecture. 2016;3(14):1-15.

22. Salama A. The Impact of Economic Diversification on Urban Morphologies in Doha: An Interdisciplinary Assessment. Qatar Foundation Annual Research Forum Proceedings. Qatar. 2013.

23. Salama A, Wiedman F. On Architecture and Urbanism in an Emerging City. Demystifying Doha, Routledge, London; 2013.

24. Salama AM. Contemporary Qatari Architecture as an Open Textbook Archnet-IJAR. 2007;1(3):112.

25. Wiedmann F, Mirincheva V, Salama. AM Urban Reconfiguration and Revitalisation: Public Mega Projects in Doha's Historic Centre. Open house international. 2012;38(4):27-36.

26. Petruccioli A, Pirani KK. Understanding Islamic Architecture. Routledge, London, England; 2003. 
27. Furlan R, Zaina S. Urban Planning in Qatar: Strategies and Vision for the Development of Transit Villages in Doha. Australian Planner 2016;1-16.

28. Dierwechter Y. Smart city-regionalism across Seattle: Progressing transit nodes in labor space? Geoforum. 2013;49:139-149.

29. Miller JS, Hoel LA. The "smart growth" debate: Best practices for urban transportation planning. Socio-Economic Planning Sciences. 2002;36(1):1-24.

30. Wey WM, Hsu J. New urbanism and smart growth: Toward achieving a smart National Taipei University District. Habitat International. 2014;42:164-174.

31. Zook JB, Lu Y, Glanz K, et al. Design and pedestrianism in a smart growth development. Environment and Behavior. 2012;44(2):216-234.

32. Carmona M, Tiesdell S, Heath T, et al. The Dimension of Urban Design. Public Places Urban Spaces, Taylor \& Francis Ltd, New York, USA; 2010.

33. Brown LJ, David D, Oliver G. Shaping More Liveable, Equitable and resilient Cities. Urban Design for an Urban Century,

1. Wiley, New Jersey, USA; 2014.

34. Cuthbert A. Critical Readings in Urban Design. Designing Cities, WileyBlackwell, UK; 2003.

35. Farr D. Urban Design with Nature. Sustainable Urbanism, Wiley, USA; 2008.

36. Zyscovich B, Porter DR. Getting Real about Urbanism, Contextual Design for Cities. Urban Land Institute, Washington, USA; 2008. p. 137.

37. Rapoport A. The Meaning of the Built Environment: A Nonverbal Communication Approach. Sage Publications, Beverly Hills, California, USA; 1990.

38. Rapoport A. Systems of Activities and Systems of Settings. In: S Kent, editor. Domestic Architecture and the Use of Space: an Interdisciplinary Cross-cultural Study, Cambridge Univeristy Press, Cambridge, UK; 1997. p. 9-20

39. Rapoport A. Reconsideration Culture-Meaning-Architecture: Critical Reflections on the Work of Amos Rapoport. In KD Moore, editors. Culture and Built Form, Brookfield Ashgate Publishing Company, UK; 2000 .

40. Rogers R, Gumuchdjjan P. Cities for a Small Planet. Faber and Faber Limited, London, England; 1996.

41. Sommer R. Social Design: Creating Buildings with People in Mind Englewood Cliffs Prentice-Hall, Australia; 1983.
42. Smith R, Bugni V. Designed Physical Environments as Related to Selves, Symbols and Social Reality: a Proposal for a Humanistic Shift for Architecture. Humanity and Society. 2002;26(4):293-311.

43. Smith R, Bugni V. Symbolic Interaction Theory and Architecture. Symbolic Interaction. 2006;29(3):124-155.

44. Flanagan WG. Urban Sociology, Images and Structure. Rowman \& Littlefield Publishers, New York, USA; 2010.

45. Handy SL, Boarnet MG, Ewing R, et al. How the Built Environment affects Physical Activity: views from Urban Planning. Am J Prev Med. 2002;2S:64-73.

46. Hutchison R, Gottdiener M, Ryan MT. The New Urban Sociology. Westview Press, USA; 2014

47. Zook JB, Lu Y, Glanz K, et al. Design and pedestrianism in a smart growth development. Environment and Behavior. 2012;44(2):216-234.

48. Lerum V. Learning from nineteenth-century innovations. Sustainable Building Design, Routledge, UK; 2016.

49. Morgan M. Vitruvius, The Ten Books on Architecture. Kessinger Publishing, New York, USA; 2005.

50. Nöth W. Handbook of Semiotics. Indianapolis Indiana University Press, USA; 1990.

51. Schoenauer N. History of Housing. McGill University Printing Service, Montreal, USA; 1992.

52. Rossi A, Eisenmann P, Ghirardo D, et al. The Architecture of the City. The MIT Press, New York, USA; 1994.

53. Zevi B. Architecture as Space: How to look at Architecture. Einaudi, Torino, Italy; 1993

54. Kaspirin R. The Composition of Complexity. Journal of Urban Design New York. 2013;18(3):449-456.

55. Falahat S. New Conceptualisation of the Urban Logic of the "Islamic city". Re-imaging the City A, Springer, USA; 2014. p. 216.

56. Petruccioli A, Pirani KK. Understanding Islamic Architecture. Routledge, London, England; 2003.

57. Shaftoe H. Creating Effective Public Places. Convivial Urban Spaces, Earthscan, London, England; 2008.

58. Day K. New urbanism and the challenges of designing for diversity. Journal of Planning Education and Research. 2003;23(1):83-95. 